\title{
Silica-Alginate Beads for Intestinal Ketoprofen Delivery
}

\begin{abstract}
MARILENA PETRESCU ${ }^{1}$, RAUL AUGUSTIN MITRAN², CRISTIAN MATEI*, MARIUS RADULESCU ${ }^{1}$, DANIELA BERGER ${ }^{1}$
IUniversity Politehnica of Bucharest, Department of Inorganic Chemistry, Physical-Chemistry and Electrochemistry, 1-7 Polizu Str., 011061, Bucharest, Romania

2llie Murgulescu Institute of Physical-Chemistry, Romanian Academy, 202 Splaiul Independentei, 060021, Bucharest, Romania

Herein, studies on ketoprofen delivery systems based on silica-alginate beads developed for the drug intestinal release for reducing its side effects were reported. The influence of surface properties, pore size and geometry of mesoporous silica carriers on the ketoprofen release kinetics was studied by using pristine and 3-aminopropyl functionalized MCM 41 (Mobile Composition of Matter) and MCF (mesocellular foam silica) materials. The ketoprofen loaded mesoporous silica coated with alginate is a pH-triggered system able to slow down the drug release rate in the targeted environment.
\end{abstract}

Keywords: mesoporous silica, ketoprofen, drug delivery systems, gastric protection, alginate

Many research efforts have been focused on drug delivery systems (DDS) due to their therapeutic efficiency [14]. Mesoporous silica is intensively studied as carrier in DDS for its outstanding properties: high specific surface area and total pore volume providing a good loading capacity of biologically active molecules, an ordered pore framework with narrow pore size distribution useful in sustained drug release and the possibility to modify the silica surface properties through functionalization in order to tailor the interactions between the support and guest molecules for desired drug delivery kinetics [4-6].

Ketoprofen, an analgesic, antipyretic and non-steroidal anti-inflammatory therapeutic agent, is orally administrated three or four times per day in the treatment of rheumatoid arthritis and osteoarthritis, [ 7-9] although it has severe side effects like anorexia, peptic ulceration or bleeding and a very short half-life, which limit its use [10-12]. In order to avoid the ketoprofen delivery in stomach and to reduce its side effects, new pharmaceutical formulations should be obtained. Attempts were made to develop various ketoprofen delivery systems, including mesoporous silica carriers [13]. The hydrophobic pore surface of pristine silica matrix can interact with ketoprofen molecules only through van der Waals forces or hydrogen bonding, but the aminopropyl (APTES) functionalized silica can establish stronger interactions of acid-base nature (scheme 1).

This was proved in a study focused on the development of ketoprofen delivery systems based on pristine and 3 aminopropyl functionalized SBA-15 mesoporous silica. The adsorption of ketoprofen on functionalized SBA-15 matrix, up to $20 \%(w t)$, was proportional to the amount of aminopropyl groups bonded on silica. Also, a slower kinetics of drug release from functionalized SBA-15 than from pristine one in simulated gastric fluid ( $\mathrm{pH} 1.2)$, acetic buffer
( $p H$ 4.5) and phosphate buffer ( $p H$ 8.4) was observed [14]. Silion et al. reported a better gastric tolerance of ketoprofen by its intercalation into layered double hydroxides, MgAlLDH and ZnAlLDH, through ionic exchange. In vivo studies on the analgesic efficacy of ketoprofen intercalated into layered double hydroxides demonstrated a slightly higher antinociceptive effect, maintained for longer periods of time when compared with ketoprofen alone, especially in the case of MgAlLDH [15]. Another ketoprofen delivery system based on hydrophilic, biodegradable poly(vinyl alcohol) nanofibers was proposed by Kenawy et al. [16].

Alginate forms two types of gels, depending on $\mathrm{pH}$, one with high viscosity in acidic solution and an ionotropic swelled gel in basic medium. Because of this feature and its ability to entrap different biomolecules it was exploited as carrier for various therapeutic agents, proteins, cells or enzymes [17, 18]. Alginate is a natural polysaccharide polymer, isolated from seaweeds, consisting in $\beta$-Dmannuronate and $\alpha$-L-glucuronate blocks arranged in an alternating structure [19]. Sodium alginate is soluble in water, but the network is stabilized, and alginate beads are formed in calcium dichloride solution, by crosslinking of the two type polymer chains with $\mathrm{Ca}^{2+}$ ions [20]. The beads are insoluble in acidic environment, preventing the release of loaded therapeutic agent in gastric fluid $(\mathrm{pH} 1.2)$ and allowing the drug to reach the intestinal tract [21]. Athigher $\mathrm{pH}$, in intestinal fluid ( $\mathrm{pH}$ 7.4), the alginate beads swell and allow the delivery of loaded biologically active guest molecules in the intestine [22, 23].

Herein, we report for the first time the development of ketoprofen delivery systems based on silica-alginate beads designed to prevent the delivery of therapeutic agent in gastric fluid and thus to diminish its severe side effects, such as stomach haemorrhagic lesions.

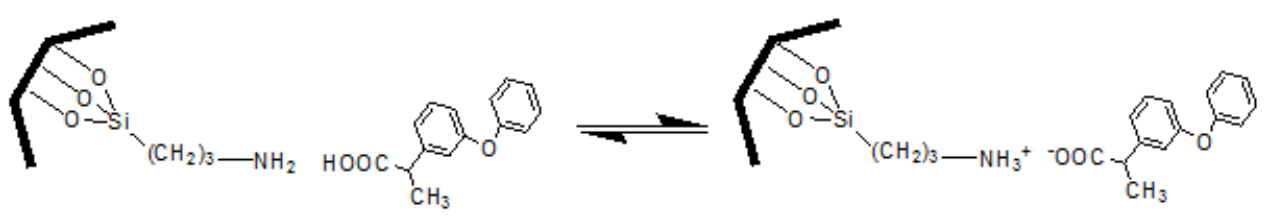

Scheme. 1. Interactions between ketoprofen and aminopropyl functionalized silica

*email:cristi_matei@yahoo.com 


\section{Experimental part}

\section{Materials}

Tetraethylorthosilicate (TEOS, Fluka), 3-aminopropyl triethoxysilane ( $98 \%$, Aldrich), hexadecyltrimethyl-ammonium bromide (CTAB, Fluka), ammonia aqueous solution 25\% (Scharlau), hydrochloric acid 36.5-38\% (Sigma), 1,3,5trimethylbenzene (TMB, Sigma-Aldrich), poly(ethylene glycol)-block-poly( propylene glycol)-block-poly(ethylene glyCol), E020PO70EO20 (Pluronic P123, average molecular weight 5800, Sigma-Aldrich), toluene (Sigma-Aldrich), ammonium nitrate ( $\geq 98 \%$, Sigma-Aldrich) and ketoprofen ( $\geq 98 \%$, Sigma) were used as received without further purification. Ultrapure water (Millipore Direct-Q3 UV water purification system with Biopack UF cartridge) was used for all aqueous solutions and in vitro drug delivery experiments. A simulated intestinal body fluid, $\mathrm{pH} 7.4$, was prepared according to literature [24] from $8.035 \mathrm{~g}$ sodium chloride (Sigma-Aldrich), $0.355 \mathrm{~g}$ sodium bicarbonate (SigmaAldrich), $0.225 \mathrm{~g}$ potassium chloride (Sigma-Aldrich), 0.231 $\mathrm{g}$ potassium phosphate dibasic trihydrate (Fluka), $0.311 \mathrm{~g}$ magnesium chloride hexahydrate (Sigma), $39 \mathrm{~mL}$ hydrochloric acid 1 M, 0.292 g calcium chloride (Sigma Aldrich), 0.072 g sodium sulfate (Sigma), $6.118 \mathrm{~g}$ tris(hydroxymethyl) aminomethane (Sigma-Aldrich) dissolved in $1 \mathrm{~L}$ of ultrapure water and used for in vitro experiments.

\section{Synthesis of mesoporous carriers}

The synthesis of pristine mesoporous silica, MCM-41 [25] and MCF (mesocellular foam silica) [26], was performed according to the methods already reported by our group. In brief, MCM-41 carrier was obtained in basic aqueous solution, $\mathrm{pH}=10$, using $\mathrm{CTAB}$ as structure directing agent, in a molar ratio TEOS : CTAB : NH3 : H2O = $1: 0.147: 3.19$ : 149. After the aging step performed at $40^{\circ} \mathrm{C}, 24 \mathrm{~h}$, a hydrothermal treatment at $150^{\circ} \mathrm{C}, 24 \mathrm{~h}$ was applied. The structure directing agent was removed by extraction in two steps, the first one in NH4NO3 alcoholic solution and the second one in $4 \% \mathrm{HCl}$ ethanolic solution. The pristine MCF material was obtained in acidic medium by using TEOS as silica precursor, Pluronic P123 as template and trimethyl benzene as swelling agent, in the molar ratio TEOS : Pluronic $\mathrm{P} 123: \mathrm{HCl}: \mathrm{TMB}: \mathrm{H} 2 \mathrm{O}=1: 0.016: 6.21: 0.432: 184$. The reaction mixture was aged at $40^{\circ} \mathrm{C}$ for $20 \mathrm{~h}$, hydrothermally treated at $105{ }^{\circ} \mathrm{C}$ for $24 \mathrm{~h}$ under auto generated pressure and then the recovered and washed solid was calcined in air, at $550^{\circ} \mathrm{C}$ for $6 \mathrm{~h}$.

The functionalized mesoporous silica with 3 aminopropyl groups (samples denoted MCM APTES and MCF-APTES) were obtained by the post-grafting approach using MCM 41 and calcined MCF materials as pristine matrices. Firstly, $0.15 \mathrm{~g}$ silica particles were dried in vacuum for $1 \mathrm{~h}$ at $110^{\circ} \mathrm{C}$ and then dispersed in $5 \mathrm{~mL}$ toluene in an ultrasound bath at room temperature. Separately, $0.058 \mathrm{~mL}$ 3-aminopropyl triethoxysilane were dissolved in $2.5 \mathrm{~mL}$ toluene and added to the silica particles suspension. The reaction mixture was kept at $50^{\circ} \mathrm{C}$ for $24 \mathrm{~h}$. The silica functionalized particles were separated by centrifugation, sequentially washed with toluene and ethanol and dried in air at room temperature. The content of 3-aminopropyl groups linked to the silica pore walls was determined by thermal analysis (DTA-TG) considering only the weight loss recorded for temperatures higher than $110^{\circ} \mathrm{C}$, as below this temperature water molecules desorption takes place.

\section{Preparation of drug-loaded materials}

The ketoprofen-loaded mesoporous silica carriers with a drug content of $20 \%$ (wt.) (samples labeled keto@ carrier) or 40\% (wt.) (samples denoted keto40@carrier) were ob- tained by incipient wetness impregnation method using a drug solution in 2-propanol. $80 \mathrm{mg}$ mesoporous support was contacted with the corresponding volume of ketoprofen solution ( $10 \mathrm{mg} / \mathrm{mL}$ ), homogenized by mixing and then the suspension was vacuum dried for $12 \mathrm{~h}$.

\section{Preparation of ketoprofen-silica-alginate beads}

The ketoprofen-silica-alginate beads were obtained by ionotropic gelation technique. Into $20 \mathrm{~mL}$ sodium alginate aqueous solution ( $2 \% \mathrm{wt}$ ), $0.1 \mathrm{~g}$ ketoprofen-loaded silica were slowly added under magnetic stirring (600 rpm), at room temperature for $0.5 \mathrm{~h}$, to obtain a homogeneous suspension. Then, the resulted suspension was dropped into $40 \mathrm{~mL}$ of $3 \%$ (wt) calcium chloride aqueous solution, magnetically stirred ( $200 \mathrm{rpm}$ ) at $5{ }^{\circ} \mathrm{C}$ using a 22 guage needle connected to the rubber tube of a peristaltic pump (Ismatec MCP Process) at $2.5 \mathrm{~mL} / \mathrm{min}$ pumping rate. The resulted beads were allowed to cure into the gelation medium for 30 minutes and then they were three times washed with acidic aqueous solution, separated by decantation and dried in air, at room temperature.

The drug content in ketoprofen-silica-alginate beads was determined by UV-vis spectroscopy (Shimadzu UV1800 spectrometer) computed as difference between the initial amount of ketoprofen-loaded into the silica support and the quantity of therapeutic agent lost in calcium chloride solution after the beads formation and in washing waters.

\section{In vitro release experiments}

The in vitro ketoprofen release experiments from either mesoporous silica supports or silica-alginate beads were carried out in ionic phosphate buffer solution (PBS), pH 7.4, at $37^{\circ} \mathrm{C}$ and $150 \mathrm{rpm}$ magnetic stirring using a dialysis membrane bag (dialysis tubing cellulose membrane, molecular weight cut-off 14,000, purchased from Aldrich). All desorption experiments were performed by immersing, in $90 \mathrm{~mL}$ PBS, the dialysis bag loaded with ketoprofen-silica sample containing the same amount of the therapeutic agent (10 $\mathrm{mg}$ ) and $1 \mathrm{~mL}, \mathrm{PBS}$, simulating the intestinal fluid. Periodically, small volumes of the dialyzing fluid were withdrawn, corresponding diluted with fresh PBS, and analyzed by UVVis spectroscopy in order to compute the released drug amount.

\section{Materials characterization}

The carriers and ketoprofen-loaded mesoporous silica were investigated through: small- and wide-angle X-ray diffraction (XRD), FTIR spectroscopy and N2 adsorptiondesorption isotherms. The small- and wide-angle XRD patterns were recorded by using a Rigaku MiniFlex II diffractometer with $\mathrm{Cu}-\mathrm{K} \alpha$ radiation in the rage of $2 \theta=1.2^{\circ}$ $6.0^{\circ}$ and $6^{\circ}-50^{\circ}$, respectively with a scanning rate of $0.5^{\circ} \%$ $\mathrm{min}$. and a step of $0.01^{\circ}$. FTIR spectroscopy was carried out on a Bruker Tensor 27 spectrometer in the $4000-400 \mathrm{~cm}^{-1}$ wavenumber range ( $\mathrm{KBr}$ pellets technique). The nitrogen adsorption-desorption isotherms were measured at liquid nitrogen temperature on a Quantachrome Autosorb iQ2 surface and porosity analyzer for determining the textural properties of both carriers and ketoprofen-loaded silica samples. Before recording the isotherms, all samples were outgassed $17 \mathrm{~h}$ under vacuum. The specific surface area values, SBET, were calculated by the Brunauer-EmmettTeller (BET) method in the 0.1-0.25 relative pressure range from the isotherms adsorption branch and the total pore volume was measured at $\mathrm{P} / \mathrm{P} 0=0.9900$.

The content of aminopropyl groups linked on the silica pore walls was determined by thermal analysis (DTA-TG) performed in air, at a heating rate of $10^{\circ} \mathrm{C} / \mathrm{min}$ from $20^{\circ}$ to $1000^{\circ} \mathrm{C}$, on a Mettler Toledo GA/SDTA85le equipment. The 
ketoprofen-silica alginate beads were characterized by thermal analysis (DTA-TG) performed in the same conditions as for functionalized silica supports and by scanning electron microscopy coupled with energy dispersive $X$-ray spectroscopy (SEM-EDX) using Tescan Vega 3 LM electron microscope.

\section{Results and discussions}

Characterization of supports and ketoprofen-loaded mesoporous silica samples

The influence of mesoporous silica support properties (pore size and geometry, surface functionalization, the drug content) on the ketoprofen delivery kinetics was studied. Ketoprofen-loaded silica was then incorporated into alginate beads and the drug release kinetics from these complex composite carriers into simulated intestinal fluid ( $\mathrm{pH}$ 7.4) was determined.

For obtaining drug-loaded silica materials, the therapeutic agent was adsorbed into the mesopores of silica-type carriers by incipient wetness impregnation method. In order to study the influence of pore array geometry, two different pristine silica carriers were used, MCM 41 with an ordered 1D hexagonal cylindrical pore array, presenting a pore diameter of $2.8 \mathrm{~nm}$ and a total pore volume of $1 \mathrm{~cm}^{3} /$ $\mathrm{g}$, and MCF exhibiting a higher porosity with a total pore volume up to $3.25 \mathrm{~cm}^{-3} / \mathrm{g}$ [26] as a result of a continuous three-dimensional disordered pore framework consisting of large spherical pores interconnected bysmaller windows [27]. MCF-type silica has the capacity to accommodate a larger amount of guest molecules into its mesopores than MCM-41 or SBA-15. Nevertheless, there are only few studies on MCF silica used as carrier in drug delivery systems, comparing to MCM-41 and SBA-15, especially for poorsoluble therapeutic agents [28, 29]. Two aminopropyl functionalized silica materials, MCM-APTES and MCFAPTES, with similar content of organic moieties, were also employed in order to enhance the acid-base interactions between ketoprofen molecules and silica support. The aminopropyl groups content, determined from thermogravimetric analysis of functionalized silica samples, was $12 \%(w t)$ and $12.4 \%$ (wt.) for MCM-APTES and MCF APTES, respectively.

The supports and ketoprofen-silica samples were investigated by small- and wide-angle XRD, FTIR spectroscopy and N2 adsorption-desorption isotherms. The successful functionalization of silica carrier with aminopropyl groups was proved by FTIR spectroscopy, which evidenced the characteristic vibrations of aminopropyl groups: 3445 $\mathrm{cm}^{-1}\left(v_{s} \mathrm{NH}\right), 1535 \mathrm{~cm}^{-1}\left(\delta \mathrm{NH}_{2}\right), 1470 \mathrm{~cm}^{-1}\left(\delta \mathrm{CH}_{2}\right), 2930$ $\mathrm{cm}^{-1}\left(v^{\mathrm{s}} \mathrm{CH}\right), 2855 \mathrm{~cm}^{-1}\left(v_{\mathrm{s}} \mathrm{CH}\right)$ and $695 \mathrm{~cm}^{-1}\left(\gamma_{\mathrm{CH}_{2}}\right)^{2}$ fig. $1 \mathrm{~b}$ and $c$ ) $\left.{ }^{5} 30\right]$. The small-angle XRD patterns of pristine and functionalized MCM-41-type silica materials showed an ordered mesophase with a hexagonal 1D symmetry for the pore array (fig. 2a and b), while a disordered one being characteristic for MCF materials [26].

In all FTIR spectra of ketoprofen-silica composites (fig. $1 d-h)$, one can observe the silica bands: asymmetric and symmetric stretching vibrations of Si-O-Si bonds at 1085 $\mathrm{cm}^{-1}$ and $800 \mathrm{~cm}^{-1}$, respectively, the vibrations of silanol groups at $960 \mathrm{~cm}^{-1}$, the deformation bands of Si-O at 460 $\mathrm{cm}^{-1}$, the vibrations of physically adsorbed water molecules at $1650 \mathrm{~cm}-1$ and the stretching vibrations of $\mathrm{OH}$ groups associated through hydrogen bonding in the range of $3200-$ $3600 \mathrm{~cm}^{-1}$, besides the specific bands of ketoprofen in the range of $2850-2950 \mathrm{~cm}^{-1}$ attributed to the methylene groups, $1720 \mathrm{~cm}^{-1}$ and $1660 \mathrm{~cm}-1$ assigned to the asymmetric and symmetric stretching vibration of carboxyl groups (fig. 1a) [30].

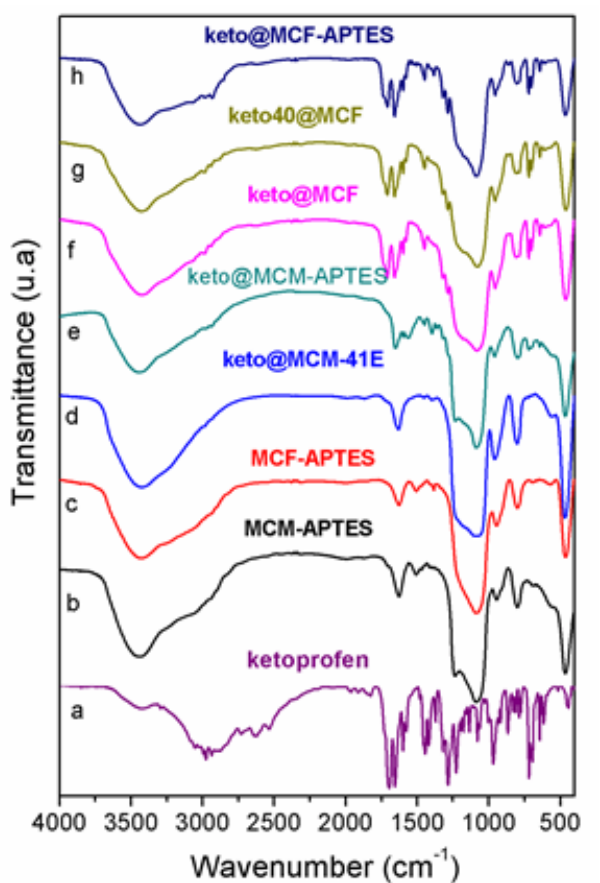

Fig. 1. FTIR spectra of ketoprofen (a), functionalized silica carriers ( $b$ and c) and ketoprofen-loaded silica samples (d-h)

The small-angle XRD of ketoprofen-loaded MCM samples exhibit the intense (100) and less intense (110) and (200) Bragg reflections demonstrating the preservation of hexagonal mesostructure of MCM-41 supports (fig. $2 \mathrm{c}$ and d) after the drug encapsulation. The diffraction peaks of crystalline ketoprofen are not present in the wide angle XRD patterns of the drug-loaded silica samples (fig. 3), indicating that the drug molecules were absorbed into the silica mesopores in amorphous state and crystalline ketoprofen was not formed on the silica surface.

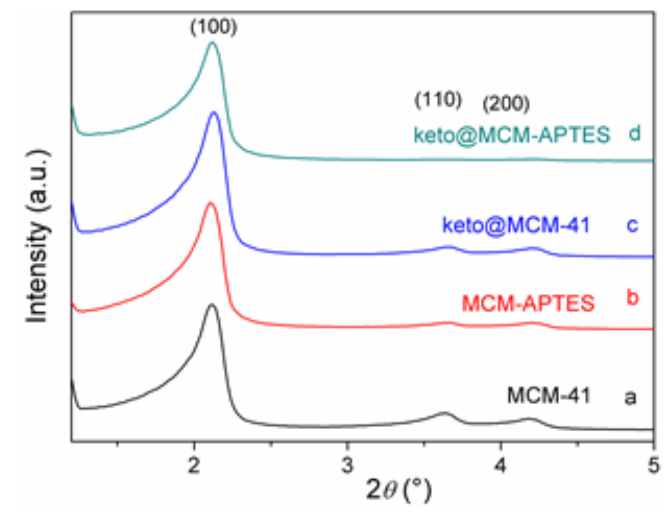

Fig. 2. Small-angle XRD patterns of MCM-41-type silica carriers and ketoprofen-loaded samples

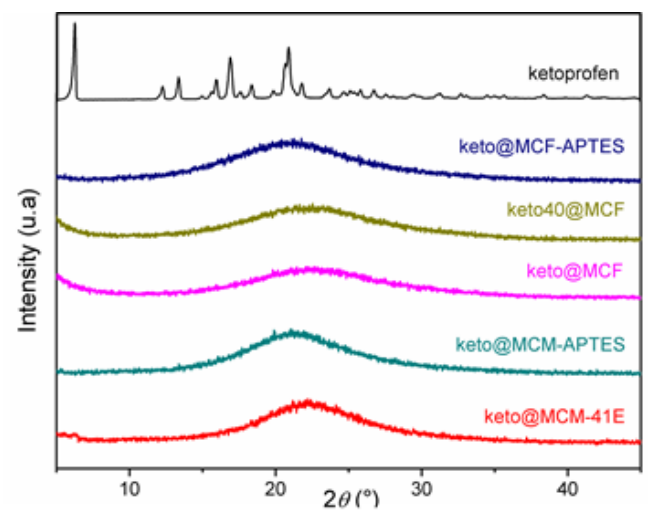

Fig. 3. Wide-angle XRD patterns of ketoprofen-loaded silica samples and ketoprofen 
The mesoporous silica supports and ketoprofen-loaded silica materials exhibit type IV N2 adsorption-desorption isotherms, characteristic for mesoporous materials, completely reversible for MCM-41-type samples (fig. 4A) and with a large $\mathrm{H} 1$ hysteresis loop for MCF-based materials because of sharp capillary condensation in the $0.65-0.9$ relative pressure range (fig. 5A). The adsorption desorption isotherms of ketoprofen-loaded silica materials prove the adsorption of drug molecules into the support mesopores, their total porosity being lower than that of the corresponding carrier (fig. $4 \mathrm{~A}$ and fig. 5A). The textural parameters (specific surface area, SBET, total pore volume, $\mathrm{V}_{\text {pore }}$ and average pore diameter, $\mathrm{d}$ ) determined from $\mathrm{N}_{2}$ adsorptiondesorption isotherms for the ketoprofen-loaded silica samples are shown in table 1 in comparison with silica carriers. Both 3-aminopropyl functionalized silica supports present lower specific surface area and average pore diameter than the pristine silica materials from which they were obtained meaning that the organic moieties are linked on the internal silica pore walls surface (table 1). Although the functionalization with aminopropyl groups of silica materials caused a slight decrease of textural parameter values, all supports exhibited large porosity required for their application as vehicles for biologically active molecules. The samples containing ketoprofen presentsome porosity, which diminished with the increase of therapeutic agent content. The pore size distribution curves and average pore diameter were calculated using Barrett-J oyner-Halenda (B) H) method for MCM-41-type samples from the desorption branch of isotherms (fig. 4B) and DFT model for MCFtype materials (fig. 5B). One can observe a decrease of the average pore diameter of drug-loaded materials compared with that of the corresponding carrier (fig. 5B and 6B) because of either the ketoprofen adsorption into carrier mesopores or the interactions between drug molecules and silica-type support (table 1).

\section{Ketoprofen release profiles from mesoporous silica carri- ers}

The determination of ketoprofen in vitro release profiles from mesoporous silica carriers was performed in intestinal simulated fluid, saline PBS, $p H 7.4$, at $37^{\circ} \mathrm{C}$, under constant magnetic stirring using a dialysis membrane. The ketoprofen dissolution test was carried out in the same conditions also using a dialysis bag. The drug delivery profiles are plotted in figure 6, as drug cumulative release with respect to the time.

The therapeutic agent exhibited fast release kinetics from pristine silica carriers in the first hour of experiment, even faster than its dissolution, in the case of keto@MCF, followed by a sustained release, more pronounced in the case of aminopropyl-functionalized silica supports due to

\begin{tabular}{|c|c|c|c|c|c|c|c|}
\hline Carrier & $\begin{array}{l}S_{\mathrm{BET}} \\
\left(\mathrm{m}^{2} / \mathrm{g}\right)\end{array}$ & $\begin{array}{c}V_{\text {pore }} \\
\left(\mathrm{cm}^{3} / \mathrm{g}\right)\end{array}$ & $\begin{array}{c}d \\
(\mathrm{~nm})\end{array}$ & Drug-loaded samples & $\begin{array}{c}S_{\mathrm{BET}} \\
\left(\mathrm{m}^{2} / \mathrm{g}\right)\end{array}$ & $\begin{array}{c}V_{\text {pore }} \\
\left(\mathrm{cm}^{3} / \mathrm{g}\right)\end{array}$ & $\begin{array}{c}d \\
(\mathrm{~nm})\end{array}$ \\
\hline MCM-41E & 818 & 0.785 & 2.82 & keto@MCM-41E & 536 & 0.51 & 2.25 \\
\hline MCM-APTES & 585 & 0.51 & 2.39 & keto@MCM-APTES & 279 & 0.19 & 1.76 \\
\hline \multirow[t]{2}{*}{ MCF } & \multirow[t]{2}{*}{876} & \multirow[t]{2}{*}{2.29} & \multirow[t]{2}{*}{16.68} & keto@MCF & 377 & 1.49 & 16.09 \\
\hline & & & & \begin{tabular}{|l|} 
keto40@MCF \\
\end{tabular} & 183 & 0.87 & 13.94 \\
\hline MCF-APTES & 518 & 1.74 & 16.09 & keto@MCF-APTES & 231 & 0.95 & 10.13 \\
\hline
\end{tabular}

Table 1

TEXTURAL PROPERTIES OF CARRIERS AND DRUG-LOADED SILICA SUPPORTS
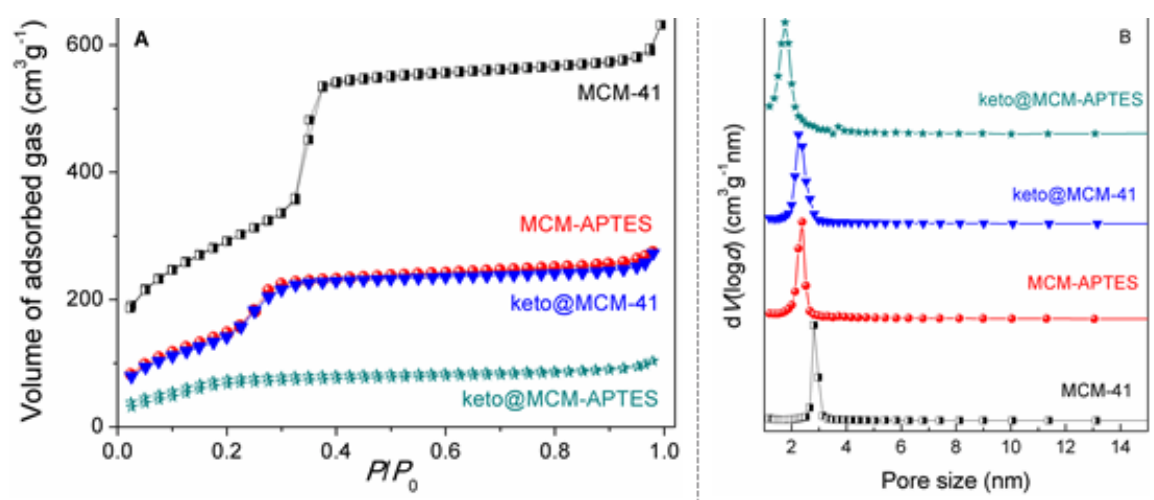

Fig. 4. $\mathrm{N}_{2}$ adsorption-desorption isotherms of MCM-41-type supports and ketoprofenloaded silica samples containing MCM-41type carriers (A) and their pore size distribution curves computed with $\mathrm{BJ} H$ model from the isotherm desorption branch

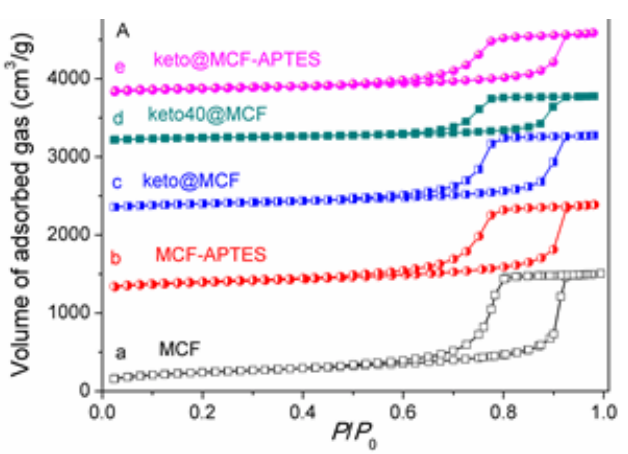

REV.CHIM.(Bucharest) 69 No. $12 \downarrow 2018$

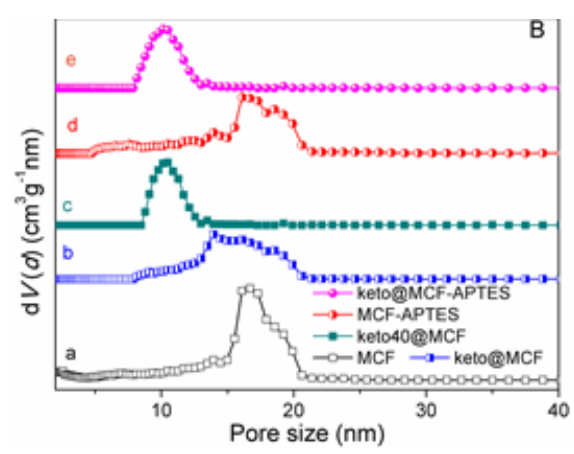

http://www.revistadechimie.ro
Fig. 5. $\mathrm{N}_{2}$ adsorption-desorption isotherms of MCF-type supports and ketoprofen-loaded MCF samples (A) and their pore size distribution curves computed with DFT model 

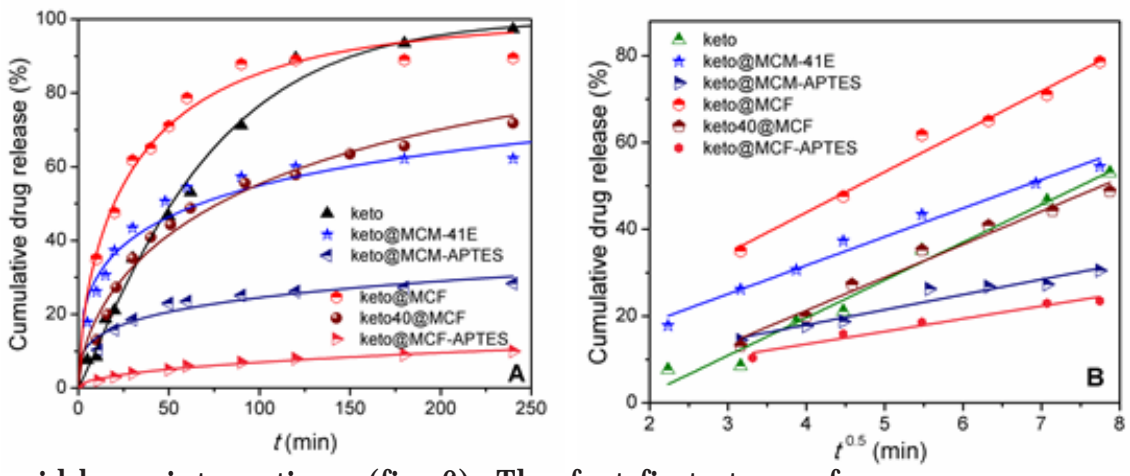

Fig. 6. Ketoprofen release profiles from pristine and functionalized silica carriers fitted with the Weibull function $(A)$ and Higuchi's model (B) acid-base interactions (fig. 6). The fast first stage of ketoprofen release from silica supports, especially for pristine ones, could be explained by the diffusion of drug molecules, which are more soluble in basic medium in amorphous state than as crystals. The second stage of ketoprofen release is slower when drug molecules, which are stronger linked on silica surface through acid-base interactions, are gradually delivery in simulated intestinal fluid. One can observe a lower drug release rate at high amount of therapeutic agent adsorbed into the mesopores of pristine MCF silica and thus, an optimum drug covering of silica pores surface is beneficial.

To get more insights on the drug transport mechanism, different kinetics models were developed [31-36]. The ketoprofen experimental release data were fitted with good correlation coefficients, $R^{2}>0.95$, using the Weibull model (eq. 1), a two parameters exponential function based on the theory of percolation in both Euclidian and fractal space (fig. 7A), which is highly applied for the drug dissolution from different matrices.

$$
m(t) / m(\propto)=1-\exp \left(-a t^{b}\right)
$$

were $m(t)$ represents the cumulative drug release at time $t, m(\alpha)$ is the total quantity of drug into supportmesopores, a parameter depends on the specific surface area through which the drug diffusion takes place and $b$ parameter indicates the transport mechanism, a Fickian diffusion in Euclidian $(0.69<b \leq 0.75)$ or fractal spaces $(b<0.69)$. table 2 lists the obtained $a$ and $b$ parameters, as well as the correlation coefficients, $R^{2}$, for the Weibull model. One can notice that the $b$ parameter values correspond to $a$ drug Fick's diffusion in fractal space, being lower than 0.69 [31].

To evaluate the ketoprofen release rate in the burststage, the drug delivery experimental data from the first hour of the experiments were fitted with the Higuchi's model: $m(t)$ / $m(\propto)=k_{H} * t^{1 / 2}$, were $k_{H}$ is the rate constant [32] (fig. 7B).
The $k_{H}$ values and the correlation coefficients, $R^{2}{ }_{H}$ obtained for all ${ }^{H}$ ketoprofen-loaded silica materials are listed in table 2. The slowest ketoprofen delivery kinetics for the burst stage of drug release was obtained in the case of MCFAPTES carrier, followed by MCM-APTES support due to the acid-base interactions between amino moieties linked on carrier mesopores surface and ketoprofen carboxyl groups. In the case of pristine silica support, lower delivery rate of ketoprofen was noticed for MCM-41E than for MCF, which could be explained by either a smaller average pore diameter and an ordered pore array or a higher content of silanol groups as the support was not calcined, unlike MCF carrier.

\section{Characterization of ketoprofen-silica-alginate beads}

To prepare drug-silica-alginate beads, keto@MCM-41E and keto@MCF APTES were chosen, both samples having $20 \%$ (wt) drug content. The chosen drug-loaded silica samples presented the lowest total cumulative release and the slowest release kinetics among pristine silica and functionalized silica carriers, respectively. The obtained ketoprofen-silica-alginate, denoted keto@MCM-alg and keto@MCF-APTES-alg, were investigated by SEM-EDX and thermal analysis. The content of ketoprofen, which remained in the silica-alginate beads was determined by measuring the drug amount delivered in calcium chloride solution during the beads formation using UV-vis spectroscopy. About a third of ketoprofen was released from either MCM-41 or MCF APTES in calcium chloride aqueous solution, resulting in a drug content of $2.2 \%(w t)$ in the alginate beads.

The SEM investigation of ketoprofen-silica-alginate composites revealed the formation of spherical beads with a diameter in the range of $0.8-1.2 \mathrm{~mm}$ (fig. 7). On the beads surface one can observe the formation of sodium chloride crystals, though the beads were intensively washed with ultrapure water (fig. 7). The EDX analysis coupled with SEM investigation showed that silica particles are inside the alginate beads, calcium ions penetrate the polymer network

Table 2

WEIBULL AND HIGUCHI PARAMETERS OBTAINED BY FITTING THE KETOPROFEN RELEASE DATA FROM SILICA CARRIERS

\begin{tabular}{|l|c|c|c|c|c|}
\hline \multirow{2}{*}{ Samples } & \multicolumn{3}{|c|}{ Weibull model } & \multicolumn{2}{c|}{ Higuchi's function } \\
\cline { 2 - 6 } & $a$ & $b$ & $\mathrm{R}^{2} \mathrm{w}$ & $k_{H}$ & $\mathrm{R}^{2} \mathrm{H}$ \\
\hline ketoprofen & 0.009 & 1.111 & 0.994 & 8.698 & 0.975 \\
\hline keto@MCM-41E & 0.157 & 0.351 & 0.951 & 6.594 & 0.979 \\
\hline keto@MCM-APTES & 0.076 & 0.284 & 0.955 & 3.498 & 0.936 \\
\hline keto@MCF & 0.1072 & 0.626 & 0.983 & 9.316 & 0.979 \\
\hline keto40@MCF & 0.0543 & 0.585 & 0.981 & 7.621 & 0.973 \\
\hline keto@MCF-APTES & 0.0082 & 0.473 & 0.972 & 2.919 & 0.956 \\
\hline
\end{tabular}



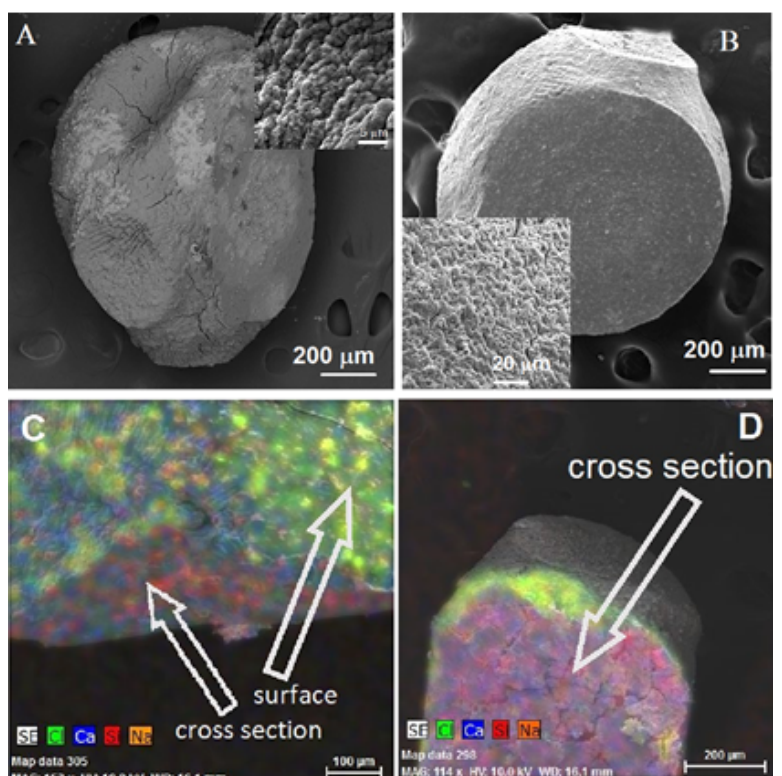

Fig. 7. SEM images of: A) keto@MCM-alg (inset its surface), B) keto@MCF-APTES-alg (inset its surface), and EDX elemental mapping of: C) keto@MCM-alg and D) keto@MCF-APTES-alg beads

and on the alginate surface there are still sodium chloride crystals.

The DTA-TG analysis of ketoprofen-silica alginate beads showed thermal decomposition in several steps (fig. 8). In the temperature range of $20^{\circ}-170^{\circ} \mathrm{C}$, both-types of beads lose water from al ginate hydrogel and silica mesopores. At $170{ }^{\circ} \mathrm{C}$, alginate begins to decompose, and the process continues up to $600^{\circ} \mathrm{C}$ [37]. Two strong exothermic effects can be noticed in the $400^{\circ}-580^{\circ} \mathrm{C}$ temperature range on the DTA curves. The residue mass for keto@MCM alg and keto@MCF-APTES-alg was $25.6 \%$ and $24.5 \%$, respectively, which consisted of $15.9 \%$ (wt) silica and $9.7 \%$ (wt) compounds containing calcium and sodium ions for the first sample and $14 \%$ and $10.5 \%$ for the second one. Ketoprofen melts at $97^{\circ} \mathrm{C}$, it is stable up to around $170^{\circ} \mathrm{C}$ and totally decomposes at $376^{\circ} \mathrm{C}[38,39]$. Because in the silica-alginate beads the content of ketoprofen is low, its thermal decomposition effect, in the temperature range of $170^{\circ}$. $376{ }^{\circ} \mathrm{C}$, is hard to notice, being overlapped with that of alginate, which is higher in the samples.

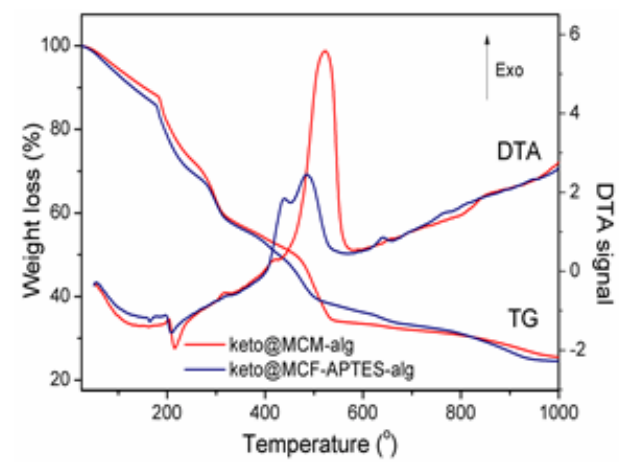

Fig. 8. DTA-TG analysis of ketoprofen-silica-alginate beads Ketoprofen release profiles from silica-alginate beads

The experiments of ketoprofen delivery from silica-alginate beads, carried out in the same conditions as for drugloaded silica samples, showed slower kinetics in comparison with the ketoprofen-loaded silica carriers. The drug release experimental data were also fitted with the Weibull function (fig. 9) with correlation coefficient of 0.977 and 0.954 for keto@MCM-alg sample and keto@MCF-APTESalg beads, respectively. The exponential b parameter of the Weibull function has values of 0.514 and 0.321 for

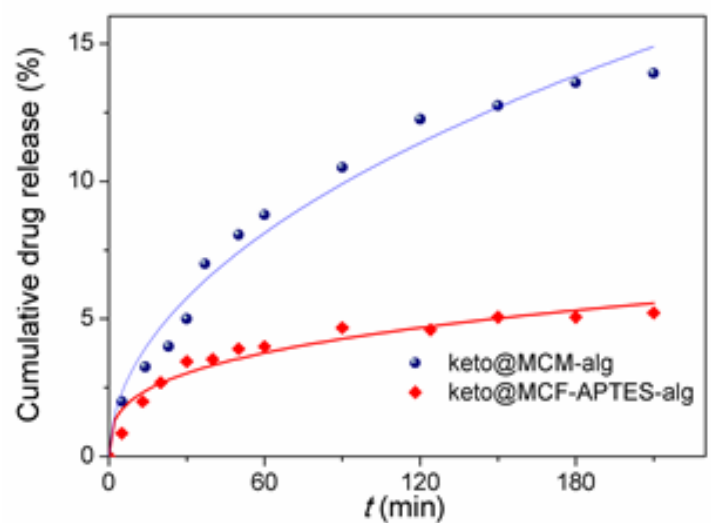

Fig. 9. Ketoprofen release profiles from silica-alginate beads fitted with the Weibull function

keto@MCM-alg and keto@MCF-APTES-alg, respectively, corresponding to a Fickian diffusion of the therapeutic agent, as in the case of the ketoprofen delivery from silicatype carriers. For both type of alginate beads, the pre-exponential parameter a of the Weibull function has the same value of 0.0103 , because it depends on the surface through which ketoprofen diffusion occurs. This can be explained by the high contribution of alginate which is in large and similar amount in both type of ketoprofen-loaded silicaalginate beads. One can notice a higher release rate of ketoprofen from MCM-alg beads than from MCF-APTESalg, the similar trend being also observed for the corresponding ketoprofen loaded silica samples.

\section{Conclusions}

Alginate coated mesoporous silica nanoparticles as carriers for ketoprofen, an anti-inflammatory drug with severe side-effects in the gastric tract, were proposed for the first time. Through avoiding the drug delivery in stomach, a better patient compliance would be approached. The mesoporous silica materials can accommodate sufficient amount of ketoprofen molecules and by tailoring the surface properties and pore size of mesoporous silica carriers, the drug delivery can be modulated. For example, a good efficiency of ketoprofen entrapment into aminopropyl functionalized silica carriers was obtained, better in the case of functionalized MCF material than for MCM-41.

By coating the ketoprofen-loaded mesoporous silica nanoparticles with alginate polymer, the drug release could be better control, offering the possibility to reach the intestinal tract and thus lowering its side-effects. Consequently, the silica-alginate beads represent promising carriers for the ketoprofen.

\section{References}

1.ZHANG, Y., CHAN, H.F., LEONG, K.W., Advanced materials and processing for drug delivery: the past and the future, Adv. Drug Deliv. Rev. 65, no. 1, 2013, p. 104

2.HOFFMAN, A.S., The origins and evolution of "controlled" drug delivery systems, J. Control. Release 132, no.3, 2008, p. 153

3.PANYAM, J., LABHASETWAR, V., Biodegradable nanoparticles for drug and gene delivery to cells and tissue, Adv. Drug Del. Rev. 55, no. 3, 2003, p. 329

4.CALDORERA-MOORE, M., GUIMARD, M.N., D-SHI, L., ROY, K., Designer nanoparticles: incorporating size, shape and triggered release into nanoscale drug carriers, Expert Oprinion in Drug Deliv. 7, no. 4, 2010, p. 479.

5.VALLET-REGÍ, M., BALAS, F., ARCOS, D., Mesoporous materials for drug delivery, Angew. Chem. Int. Ed., 46, no. 40, 2007, p. 7548

6.AL TAMEEMI, M.B.M., DOBRINESCU, R., MARTON, G., OTT, C., Doxo- 
rubicin loaded silica nanotubes: an investigation of the release behavior, U.P.B. Sci. Bull., Series B, 77, no. 3, 2015, p. 185

7.HEYNEMAN, C.A., LAWLESS-LIDAY, C., WALL G.C., Oral versus topical NSAIDs in rheumatic disease: a comparison, Drugs, 60, no. 3, 2006, p. 555

8.MARIE, R.G., Epidemiology of nonsteroidal anti-inflammatory drug associated gastrointestinal injury, Am. J. Med. 104, no. 3A, 1998, 235. 9.VUEBA M.L., PINA M.E., VEIGA F, SOUSA J. J., BATISTA DE CARVALHO L.A.E. Conformational study of ketoprofen by combined DFT calculations and Raman spectroscopy. Int. J. Pharm. 307, no. 1, 2006, p. 56. 10.KANTOR, T.G., Ketoprofen: a review of its pharmacologic and clinical properties. Pharmacotherapy 6, no. 3, 1986, p. 93.

11.MARIE, R.G., Nonsteroidal anti-inflammatory drugs: practical and theoretical considerations in their selection, Am. J. Med. 100, no. 2A, 1996, p. 31S.

12.SAVAGE R.L., MOLLER P.W., BALLANTYNE C.L., WELLS J.E., Variation in the risk of peptic ulcer complications with nonsteroidal antiinflammatory drug therapy. Arthritis Rheum., 36, no. 1, 1993, p. 84 13.MANZANO, M., AINA, V., AREAN, C.O., BALAS, F., CAUDA, V., COLILLA, M., DELGADO, M.R., VALLET-REGI, M., Studies on MCM-41 mesoporous silica for drug delivery: Effect of particle morphology and amine functionalization, Chem. Eng. J. 137, no. 1, p. 30

14.MORITZ, M., LANIECKI, M., SBA-15 mesoporous material modified with APTES as the Carrier for 2-(3-benzoylphenyl) propionic acid, Appl. Surf. Sc. 258, no.19, 2012, p. 7523

15.SILION, M., HRITCU, D., J ABA I.M., TAMBA, B., IONESCU, D., MUNGIU, O.C., POPA, I.M., In vitro and in vivo behavior of ketoprofen intercalated into layered double hydroxides, J. Mater. Sci. Mater. Med. 21, no. 11, 2010, p. 3009

16.KENAWYA, EL-R., ABDEL-HAY, F.I., EL-NEWEHYA, M.H., W NEK, G.E., Controlled release of ketoprofen from electrospun poly(vinyl alcohol) nanofibers, Mater. Sci. Eng. A 459, no. 1-2, 2007, p. 390

17.SHILPA, A., AGRAWAL, S.S., RAY, A.R., Controlled delivery of drugs from alginate matrix, J. Macromol. Sci. Part. C Polym, Rev., C43, no. 2, 2003, p. 187

18.TONNESEN, H.H., KARLSEN, J., Alginate in Drug Delivery Systems, Drug Develop. Ind. Pharm., 28, no. 6, 2002, p. 621

19.PONGJ ANYAKUL, T., SUKSRI, H. Alginate-magnesium aluminium silicate films for bucal delivery of nicotine, Coll. Surf. B Biointerfaces, 74, no. 1, 2009, p. 103

20.SHI, J., ALVES, N.M., MANO, J.F. Drug release of pH-temperatureresponsive calcium alginatepoly( $\mathrm{N}$-isopropylacrylamide) semi-IPN beads, Macromol. Biosci. 6, no. 5, 2006, p. 358.

21.DAI, Y.N., LIA, P., ZHANG, J.P., WANG, A.Q., WEI, Q. A novel pHsensitive $\mathrm{N}$-succinyl chitosan/alginate hydrogel bead for nifedipine delivery, Biopharm. Drug Dispos., 29, no. 3, 2008, p. 173

22.DAS, M.K., SENAPATI, P.C. Furosemide loaded alginate microspheres prepared by ionic crosslinking technique: morphology and release characteristics, Indian J. Pharm. Sci. 70, no. 1, 2008, p. 77

23.BERGER, D., BAJ ENARU, L., NASTASE, S., MITRAN, R.A., MUNTEANU, C., MATEI, C., Influence of structural, textural and surface properties of mesostructured silica and aluminosilicate carriers on aminoglycoside uptake and in vitro delivery, Micropor. Mesopor. Mater. 206, no. 4, 2015, p. 150
24.MARQUES, M.R.C., LOEBENBERG, R., ALMUKAINZI, M., Simulated Biological Fluids with Possible Application in Dissolution Testing, Diss. Tech. 18, no. 3, 2011, p. 15

25.NASTASE, S., BAJ ENARU, L., MATEI, C., MITRAN, R.A., BERGER, D. Ordered mesoporous silica and aluminosilicate-type matrix for amikacin delivery systems, Microporous and Mesoporous Materials, 182, no. 12, 2013, p. 32

26.MITRAN, R.A., BERGER, D., MUNTEANU, C., MATEI, C., Evaluation of different nesoporous silica supports for energy storage in shape-stabilized phase change materials with dual thermal responses, J. Phys. Chem. C, 119, no. 27, 2015, p. 15177

27.SCHMIDT-WINKEL, P., LUKENS, W.W., ZHAO, D., YANG, P., CHMELKA, B.F., STUCKY, G.D. Mesocellular siliceous foams with uniformly sized cells and windows, J. Am. Chem. Soc. 121, no.1, 1998, p. 254.

28.LEI, C., CHEN, B., LI, X., QI, W., LIU, J., Non-destructively shattered mesoporous silica for protein drug delivery, Micropor. Mesopor. Mater. 175, no. 7, 2013, p. 157

29.HAO, Y., ZHAO, J., WANG, G., CAO, L., WANG, J., YUE, F., Grafting of thermo- and $\mathrm{pH}$-responsive polymer inside mesoporous silica foam in supercritical carbon dioxide for controlled release of 5-fluorouracil, Fibers and Polymers, 18, no.12, 2017, p. 2476

30.SOCRATES, G., Infrared and Raman Characteristic Group Frequencies, 3rd ed. John Wiley and Sons, Chichester, 2001.

31.PAPADOPOULOU, V., KOSMIDIS, K., VLACHOU, M., MACHERAS, P., On the use of the Weibull function for the discernment of drug release mechanisms, Int. J. Pharm. 309, no. 1-2, 2006, p. 44.

32.SIEPMANN, J., PEPPAS, N.A. Higuchi equation: Derivation, applications, use and misuse, Int. J. Pharm. 418, no.1, 2011, p. 6.

33.MARIA, G., BERGER, D., NASTASE, S., LUTA, I., Modelling alternatives of the irinotecan release from functionalized mesoporous-silica supports, Micropor. Mesopor. Mat., 149, 2012, p. 25

34.POSTELNICESCU, P., DUMITRESCU A.M., DANCIU, T.D., Kinetic Studies on the Controlled Release of Oral Antibiotics, Rev. Chim. (Bucharest), 66, no. 10, 2015, p. 1545.

35.MITRAN, R.A., BERGER, D., PANDELE-CUSU, J., MATEl, C., Effect of Aluminum Incorporation into Mesoporous Aluminosilicate Framework on Drug Release Kinetics, Journal of Nanomaterials, 2017, Article ID 9864396

36.LUTA, I. MARIA, G., Semi-empirical vs. mechanistical kinetic models used to design drug delivery systems, U.P.B. Sci. Bull., Series B, 74, no. 2, 2012, p. 99

37.ILIESCU, R.I., ANDRONESCU, E., GHITULICA, C.D., BERGER, D., FICAI A., Montmorillonite-alginate nano-composite beads as drug carrier for oral administration of carboplatin-preparation and characterization, U.P.B. Bull. Sci. 73, no. 3, 2011, p. 2

38.TITA, B., MARIAN, E., RUSU, G., BANDUR, E., TITA, D., Effects of experimental conditions on the thermal behaviour of some non-steroidal anti-inflammatory Drugs, Rev. Chim. (Bucharest), 64, no.12, 2013, p. 1390

39.DRAGAN, F., KACSO, I., MARTIN, F., BORODI, G., BRATU, I., COSTULEANU, M., SANDU, I.G., POROCH, V., Solid state interactions between ketoprofen and excipients in solid dosage forms, Rev. Chim. (Bucharest), 67, no. 10, 2016, p. 2043.

Manuscript received: 10.01 .2018 